\title{
Article
}

\section{The fire retardant behaviour of huntite and hydromagnesite - A review}

Hollingbery, L.A. and Hull, T Richard

Available at http://clok.uclan.ac.uk/1432/

Hollingbery, L.A. and Hull, T Richard ORCID: 0000-0002-7970-4208 (2010) The fire retardant behaviour of huntite and hydromagnesite - A review. Polymer Degradation and Stability . ISSN 01413910

It is advisable to refer to the publisher's version if you intend to cite from the work. http://dx.doi.org/10.1016/j.polymdegradstab.2010.08.019

For more information about UCLan's research in this area go to

http://www.uclan.ac.uk/researchgroups/ and search for <name of research Group>.

For information about Research generally at UCLan please go to http://www.uclan.ac.uk/research/

All outputs in CLoK are protected by Intellectual Property Rights law, including Copyright law. Copyright, IPR and Moral Rights for the works on this site are retained by the individual authors and/or other copyright owners. Terms and conditions for use of this material are defined in the policies page. 


\title{
The Fire Retardant Behaviour of Huntite and Hydromagnesite - A Review
}

\author{
L.A.Hollingbery ${ }^{\mathrm{a}, \mathrm{b}^{*}}$, T.R.Hull ${ }^{\mathrm{b}}$ \\ a Minelco Ltd, Raynesway, Derby, DE217BE. Luke.Hollingbery@Minelco.com. \\ Tel: 01332673131 Fax: 01332677590 \\ ${ }^{\mathrm{b}}$ School of Forensic and Investigative Sciences, University of Central Lancashire, Preston, \\ PR1 2HE
}

Keywords: hydromagnesite, huntite, UltraCarb, fire, flame, retardant, filler, mineral

\begin{abstract}
Naturally occurring mixtures of hydromagnesite and huntite have found important industrial use. Their endothermic decomposition over a temperature range similar to that of commonly used polymers and their release of water and carbon dioxide, has led to such mixtures being successfully used as fire retardants. They have replaced aluminium hydroxide and magnesium hydroxide in many applications. The current understanding of the thermal decomposition mechanism of both minerals and their combination in natural mixtures has been reviewed and related to their fire retardant action. Both minerals contribute to the reduction in flammability of polymers although the extent of these interactions has not been fully investigated. However, the fire retardant mechanism of these minerals appears more complicated than either aluminium hydroxide or magnesium hydroxide.
\end{abstract}

This paper critically examines the literature on the fire retardant behaviour of mixtures of hydromagnesite and huntite, providing information of particular use to formulators of fire retardant polymers using these minerals. It also highlights the gaps in understanding of the fire retardant mechanisms of mixtures of hydromagnesite and huntite and areas that require further research.

\section{Metal Hydroxides and Other Mineral Fire Retardant Additives}

The largest group of mineral fire retardants are metal hydroxides. Aluminium hydroxide (ATH) and magnesium hydroxide are the most widely used[1]. Metal hydroxides act as fire retardants by releasing water vapour through endothermic decomposition leaving a thermally stable inorganic residue. When used as a filler in polymer composites they dilute the combustible polymer decomposition products with water, cooling the condensed phase through the endothermic dehydration.

Globally aluminium hydroxide is the highest tonnage fire retardant[2,3]. It decomposes according to the following reaction:

$$
2 \mathrm{Al}(\mathrm{OH})_{3(\mathrm{~s})} \rightarrow \mathrm{Al}_{2} \mathrm{O}_{3(\mathrm{~s})}+3 \mathrm{H}_{2} \mathrm{O}_{(\mathrm{g})}
$$

The endothermic loss of approximately $35 \%$ by mass of water resulting from the thermal decomposition of ATH has been variously reported[3-5] between 1170 and $1300 \mathrm{Jg}^{-1}$. The decomposition starts at about $180-200^{\circ} \mathrm{C}$ [5] depending on the particle size and physical form. ATH is only suited for polymers that are processed below its decomposition temperature and decompose close to ATH's decomposition temperature so that water release coincides with fuel release from the decomposing polymer. This limits the range of suitable applications for ATH.

Typically at least $60 \%$ by mass of ATH is needed in order to achieve good fire retardant properties[2]. Such high loading levels have a negative effect on the mechanical properties of the compound and this limits the application of metal hydroxide mineral fire retardants. 
In the limiting oxygen index test[6] the relative contribution of the enthalpy of decomposition, heat capacity of the evolved gases and the heat capacity of the residue from ATH has been shown by Rothon[5] to be $51.4 \%, 30.1 \%$ and $18.5 \%$ respectively. These figures were based on unpublished work by Case and Jackson of $\mathrm{ICI}$ and earlier work by Khalturinskii[7], in which heat balance equations were used to calculate the values. Unfortunately the only other figures given by Rothon are for nesquehonite $\left(\mathrm{MgCO}_{3} \cdot 3 \mathrm{H}_{2} \mathrm{O}\right)$, the values of which are quoted as $56.9 \%, 35.5 \%$ and $7.6 \%$ respectively. According to Rothon, nesquehonite gives off $71 \%$ of its mass as carbon dioxide and water with an enthalpy of decomposition of $1750 \mathrm{Jg}^{-1}$, compared to $34.5 \%$ and $1300 \mathrm{Jg}^{-1}$ for ATH. The relatively larger endotherm and higher mass loss of nesquehonite is consistent with the relatively greater contribution of the endotherm and heat capacity of the evolved gases as calculated by Rothon. The main reason that nesquehonite is not widely used as a fire retardant for polymers is that decomposition starts to occur at about $70^{\circ} \mathrm{C}$. The calculations only take into account the effect of the mineral fire retardant, other factors such as the char forming nature of the polymer and the heat capacity of this carbonaceous char will also influence the measured LOI value. The calculations shown in Rothon's work would need to be further developed to fully model the contribution of all components of polymer compound to the LOI value.

Magnesium hydroxide is used less widely than ATH. It also decomposes through an endothermic reaction to give off water.

$$
\mathrm{Mg}(\mathrm{OH})_{2} \rightarrow \mathrm{MgO}+\mathrm{H}_{2} \mathrm{O}
$$

The endotherm for this reaction is quoted at values between 1244 to $1450 \mathrm{Jg}^{-1}$ by various authors[3,5,8,9]. It starts to decompose at about $300-330^{\circ} \mathrm{C}$ giving off about $31 \%$ of its original mass as water[5].

The higher decomposition temperature of magnesium hydroxide means that it is better suited to polymers, such as polypropylene and polyamides[9], which are processed at temperatures above the decomposition temperature of ATH.

As with ATH high loading levels of $50-60 \%$ by mass of magnesium hydroxide are generally required to achieve good fire retardant properties in polymers.

Hornsby[10-12] has proposed that magnesium hydroxide works as a fire retardant through five main mechanisms:

1. endothermic decomposition which helps to reduce the thermal decomposition of the polymer

2. release of water vapour diluting the vapour phase

3. the heat capacity of both the magnesium hydroxide and the decomposition product, magnesium oxide, further reduces the thermal energy available to degrade the polymer

4. the decomposition products promote char formation and therefore insulate the substrate from the heat source

5. the high loading level of magnesium hydroxide acts as a solid phase diluent

In polymers such as polyethylene and polypropylene the residue will consist of a compacted powder formed mainly of magnesium oxide, very little carbonaceous char will be present. However the heat capacity of the inorganic residue will have an insulation effect on the substrate as noted in points 3 and 4 of Hornsby's list.

Hornsby also states[10] that the resultant high surface area, active magnesium oxide decomposition product acts as a smoke suppressant by absorbing carbonaceous decomposition products and possibly catalysing their oxidation. The fact that both magnesium hydroxide and aluminium hydroxide act as smoke suppressants was shown[11] in a comparison of polypropylene compounds filled with ATH, magnesium hydroxide and chalk. Both magnesium hydroxide and ATH showed lower smoke production than the chalk filled compound, meaning that the action was more than a simple dilution effect of the polymer. 
Hydrotalcites[3], also known as layered double hydroxides, belong to a series of magnesium aluminium hydroxycarbonates with varying ratios of magnesium to aluminium. Their structure consists of layers of magnesium hydroxide with aluminium interspersed within the layers. Carbonate anions are located between the layers and balance the positive charge from the aluminium cations. There have been several studies[13-16] of the fire retardant effects of these materials, although their most common usage remains as a stabiliser and acid absorber for PVC[3].

Although ATH and magnesium hydroxide are the most well known mineral fire retardants, Rothon[5] has shown that there are a number of minerals (Table 1) that could be of potential benefit in polymers. Each decomposes endothermically with the evolution of either carbon dioxide, water or both. Of these minerals, hydromagnesite is the one that has probably seen most commercial interest. Its onset of decomposition is slightly higher than ATH making it suitable for polymers where ATH has been traditionally used, as well as in compounds where ATH becomes unsuitable due to higher processing temperatures.

Mineral
Nesquehonite
Gypsum
Magnesium phosphate octahydrate
Aluminium hydroxide
Hydromagnesite
Dawsonite
Magnesium hydroxide
Magnesium carbonate subhydrate
Boehmite
Calcium hydroxide

Table 1: Minerals with potential fire retardant benefits, and their decomposition temperatures[5]

\author{
Approximate onset of \\ Decomposition $\left({ }^{\circ} \mathrm{C}\right)$ \\ $70-100$ \\ $60-130$ \\ $140-150$ \\ $180-200$ \\ $220-240$ \\ $240-260$ \\ $300-320$ \\ $340-350$ \\ $340-350$ \\ $430-450$
}

\section{Hydromagnesite and Huntite as Fire Retardant Additives}

Rothon's list of potential fire retardant minerals (Table 1) includes hydromagnesite but not huntite. Natural hydromagnesite has been discovered in mixed deposits with huntite which is the reason such mixtures have generated interest as fire retardants. Mixtures of natural hydromagnesite and huntite have been commercially exploited as fire retardants since the late 1980's. Georgiades[17] reported some of the history of one such deposit in Greece. This deposit is still exploited, although the world's largest known reserves of mixed hydromagnesite and huntite are in Turkey, operated commercially by Minelco.

There has been much work published regarding the structure[18-23] and thermal decomposition[24-39] of hydromagnesite and huntite. A recent article[40], by the current authors, reviews this body of work in detail. However a brief summary is presented here in order to explain the fire retardant behaviour of these minerals in polymer formulations.

Huntite particles have a fine highly platy structure as shown in the electron micrograph (Figure 1) produced by the current authors. Samples were gold coated and examined using a Carl Zeiss (Leo) 1530VP FEGSEM. Many of the individual particles have a diameter of 1 micron or less and thicknesses in the nanometer range. 


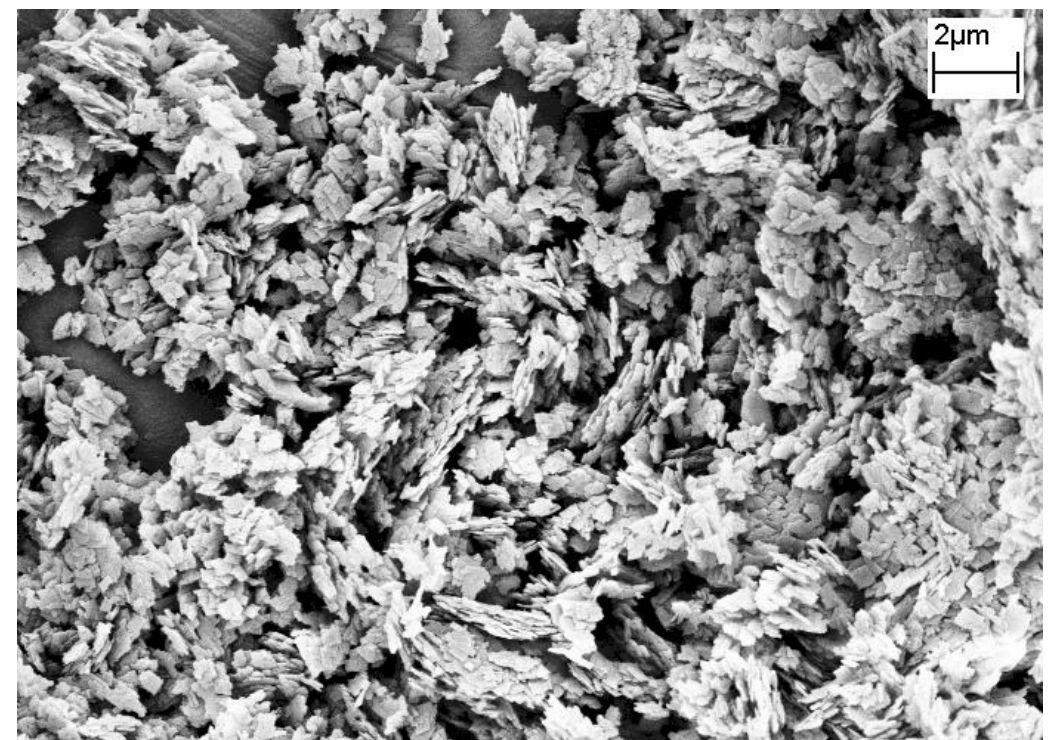

Figure 1: Huntite particles

Figure 2 (again produced by the current authors) shows a natural mixture of hydromagnesite and huntite where the larger, more blocky, hydromagnesite particles can be seen interspersed with smaller platy huntite particles.

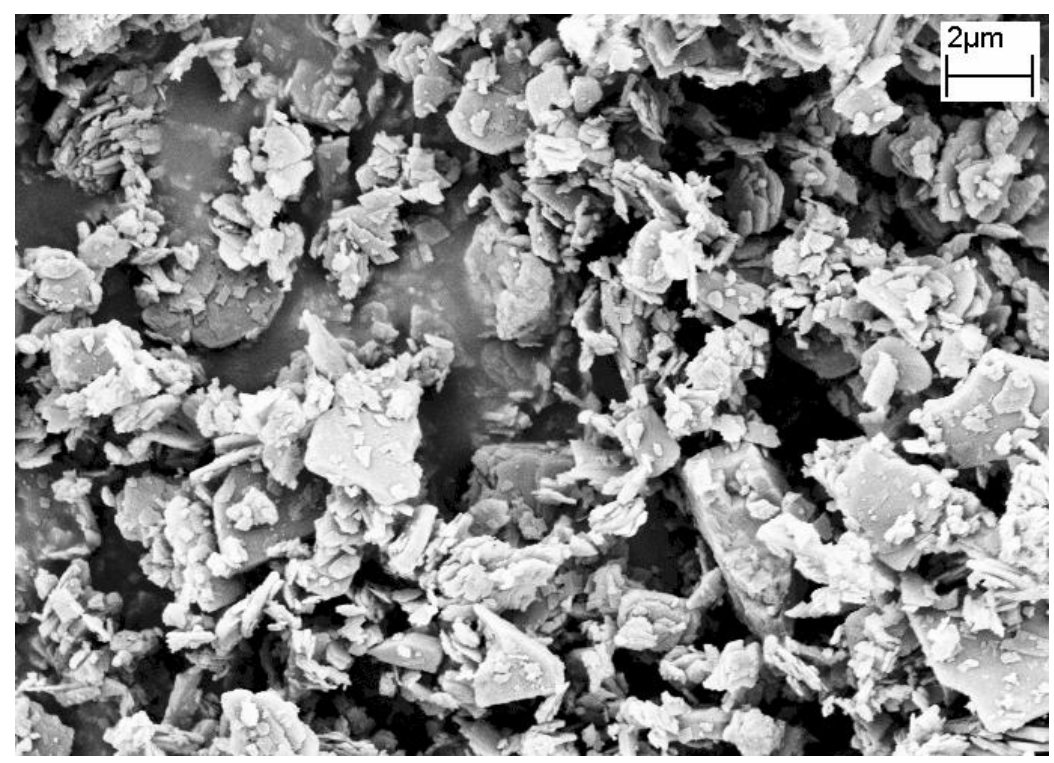

Figure 2: A mixture of hydromagnesite and huntite particles

Hydromagnesite and huntite decompose through the following endothermic reactions although there has been much discussion about the exact mechanism.

Hydromagnesite[24,25,27,33,35-39,41]

$\mathrm{Mg}_{5}\left(\mathrm{CO}_{3}\right)_{4}(\mathrm{OH})_{2} \cdot 4 \mathrm{H}_{2} \mathrm{O} \rightarrow 5 \mathrm{MgO}+4 \mathrm{CO}_{2}+5 \mathrm{H}_{2} \mathrm{O}$ 
Huntite[20,32,42,43]

$\mathrm{Mg}_{3} \mathrm{Ca}\left(\mathrm{CO}_{3}\right)_{4} \rightarrow 3 \mathrm{MgO}+\mathrm{CaO}+4 \mathrm{CO}_{2}$

Typical thermogravimetric analysis (TGA) decomposition curves measured by the current authors for natural hydromagnesite, natural huntite and a commercially available mixture of hydromagnesite and huntite produced by Minelco under the UltraCarb trade name are shown in Figure 3. The measurements were made using a TA Instruments Q5000 at a heating rate of $10^{\circ} \mathrm{C} \mathrm{min}-1$ in air.

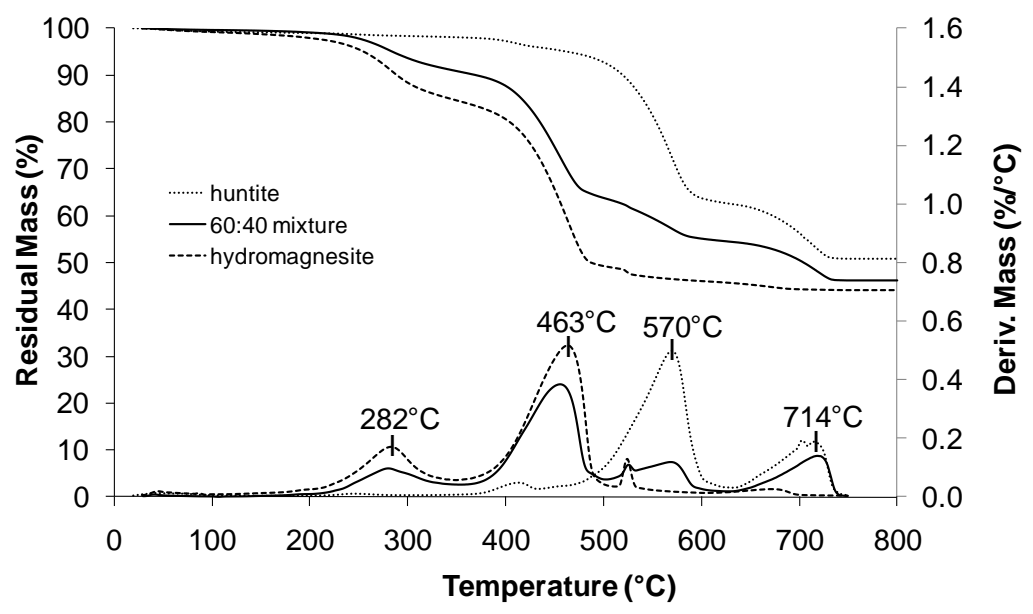

Figure 3: TGA profile of natural hydromagnesite, huntite and a 60:40 mixture of hydromagnesite and huntite.

Decomposition of hydromagnesite begins to occur at about $220^{\circ} \mathrm{C}$ and progresses through two major mass losses (Figure 3). These mass losses have been reported[24,33,35-39,44] to consist initially of the loss of water of crystallisation:

$$
\mathrm{Mg}_{5}\left(\mathrm{CO}_{3}\right)_{4}(\mathrm{OH})_{2} \cdot 4 \mathrm{H}_{2} \mathrm{O} \rightarrow \mathrm{Mg}_{5}\left(\mathrm{CO}_{3}\right)_{4}(\mathrm{OH})_{2}+4 \mathrm{H}_{2} \mathrm{O}
$$

Followed by decomposition of the hydroxide ion:

$$
\mathrm{Mg}_{5}\left(\mathrm{CO}_{3}\right)_{4}(\mathrm{OH})_{2} \rightarrow \mathrm{Mg}_{4}\left(\mathrm{CO}_{3}\right)_{4}+\mathrm{MgO}+\mathrm{H}_{2} \mathrm{O}
$$

Finally followed by decomposition of the carbonate ion:

$$
\mathrm{Mg}_{4}\left(\mathrm{CO}_{3}\right)_{4} \rightarrow \mathrm{MgO}+4 \mathrm{CO}_{2}
$$

The decomposition of the resultant magnesium carbonate to magnesium oxide has been shown to follow different mechanisms depending on the partial pressure of carbon dioxide in the atmosphere[33,36,37]. The presence of carbon dioxide causes the magnesium carbonate to crystallise[39] exothermically instead of directly decomposing. Crystalline magnesium carbonate decomposes at a higher temperature than the form of magnesium carbonate left directly after liberation of water from the crystal. The crystallisation of magnesium carbonate has also been linked to the rate of heating[31,36]. Rates of heating of greater than $18.5^{\circ} \mathrm{C}$ $\mathrm{min}^{-1}$ were reported by Khan[31] to cause exothermic crystallisation of the magnesium carbonate. Exothermic crystallisation during endothermic decomposition of a mineral is not unique to hydromagnesite. Magnesium hydroxide has also been reported[45] to show an exotherm at a little over $500^{\circ} \mathrm{C}$ due to crystallisation of cubic magnesium oxide after dehydroxylation.

The current authors' own work using TGA has confirmed the effect that heating rate has on the mass loss profile of hydromagnesite. Figure 4 shows that at a higher heating rate the 
decomposition of the carbonate, splits into two separate stages with complete decomposition occurring about $60^{\circ} \mathrm{C}$ above that observed at the slower heating rate. This is consistent with the partial decomposition of the magnesium carbonate followed by crystallisation of the remaining magnesium carbonate and decomposition of the crystalline structure at a higher temperature. When used as a fire retardant it is likely that hydromagnesite will decompose through the mechanism of crystallisation of magnesium carbonate because of the high heating rates, the self generated carbon dioxide atmosphere, and the presence of the surrounding polymer melt hindering escape of the carbon dioxide.

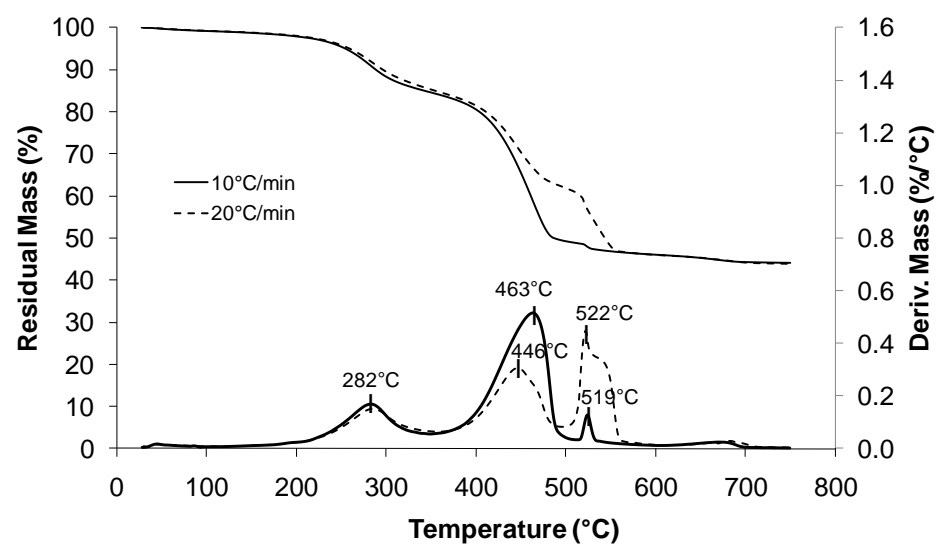

Figure 4: TGA profile of hydromagnesite at heating rates of $10^{\circ} \mathrm{C} \min ^{-1}$ and $20^{\circ} \mathrm{min}^{-1}$

Huntite begins to endothermically decompose $[20,32,43]$ at about $450^{\circ} \mathrm{C}$ and progresses through two major mass losses (Figure 3) Initially it decomposes to magnesium oxide, calcium carbonate and carbon dioxide:

$$
\mathrm{Mg}_{3} \mathrm{Ca}\left(\mathrm{CO}_{3}\right)_{4} \rightarrow 3 \mathrm{MgO}+\mathrm{CaCO}_{3}+3 \mathrm{CO}_{2}
$$

This is followed by the decomposition of calcium carbonate to calcium oxide and carbon dioxide:

$$
\mathrm{CaCO}_{3} \rightarrow \mathrm{CaO}+\mathrm{CO}_{2}
$$

A mixture of hydromagnesite and huntite therefore provides a broad decomposition range (Figure 3) starting at about $220^{\circ} \mathrm{C}$ and being complete by about $740^{\circ} \mathrm{C}$. During these decomposition reactions approximately $54 \%$ of the original mass of the mixture of hydromagnesite and huntite is released as carbon dioxide and water. The mass loss will vary slightly depending on the ratio of the two minerals.

The current authors' own work using a Rheometric Scientifics DSC1500, under a nitrogen atmosphere, with a heating rate of $10^{\circ} \mathrm{C} \mathrm{min}{ }^{-1}$ has confirmed the total heat of decomposition of UltraCarb, a commercially available mixture of hydromagnesite and huntite. Figure 5 shows that each of the decompositions measured by TGA is associated with an endotherm measured by DSC. The total heat of decomposition of the mixture is approximately $-990 \mathrm{Jg}^{-1}$. This figure will vary depending on the ratio of the two minerals. 


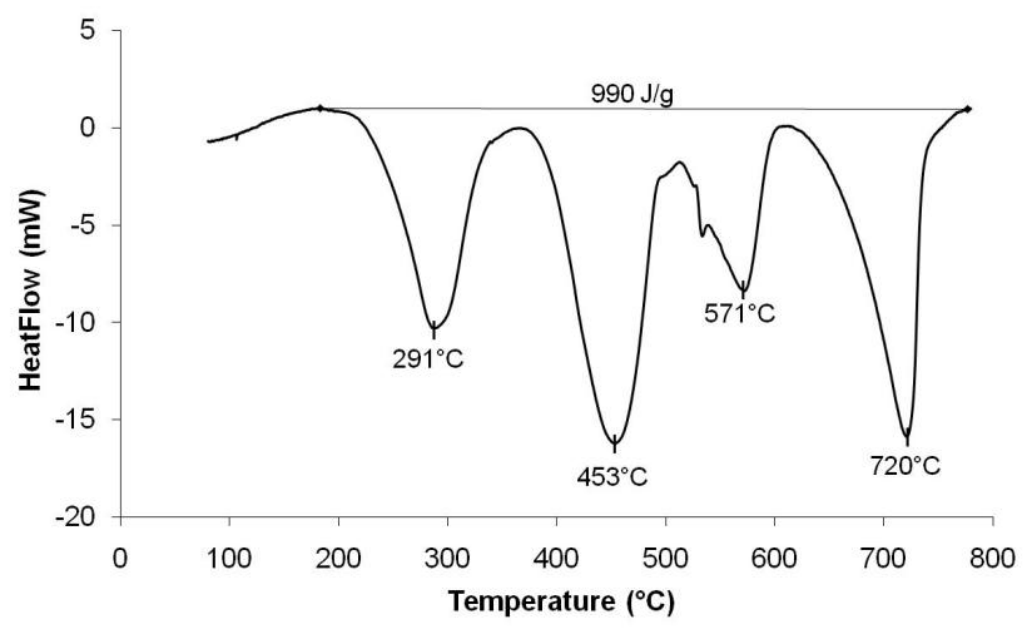

Figure 5: DSC profile of a mixture of natural hydromagnesite and huntite (UltraCarb)

Since UltraCarb is a mixture of hydromagnesite and huntite the TGA and DSC decomposition curves are a combination of the decompositions of the two minerals. This endothermic decomposition over a wide temperature range, along with the evolution of water and carbon dioxide is what has made mixtures of hydromagnesite and huntite of interest for fire retardant applications.

\section{Action of Hydromagnesite and Huntite as a Fire Retardant in Halogen Free Formulations}

In terms of fire retardancy the published literature almost exclusively refers to the use of hydromagnesite in polymers. However there have been other proposed uses of this mineral and its natural blends with huntite, such as its use to fight forest fires[46-50] and its use to control the burning rate of cigarette papers[51,52].

The first reports of mixtures of hydromagnesite and huntite as a fire retardant appeared in the trade literature. Microfine Minerals (the name used by Minelco before acquisition and renaming by Sweden's LKAB) published some work in the late 1980's and early 1990's promoting its new blends of hydromagnesite and huntite as a fire retardant mineral under the trade name UltraCarb. An article[53] appeared in the Plastics and Rubber Weekly in 1988 introducing UltraCarb as a new product consisting of a naturally occurring partially hydrated magnesium calcium carbonate. It was also stated that it could be used as an alternative to already known mineral fire retardants such as ATH and magnesium hydroxide. A similar article[54] appeared in European Plastics News the same year giving details of UltraCarb as a new mineral with claims that it could provide fire retardant and smoke suppressant properties for 'most types of plastics'. Two years later an article[55] in Modern Plastics International described UltraCarb as a 'flame retardant, smoke suppressor which is a mixture of huntite and hydromagnesite'. It goes on to explain that it absorbs heat by forming metal oxides, carbon dioxide and water and gives information on its use in ethylene vinyl acetate copolymer (EVA).

Most published research supports the view that hydromagnesite is the more effective fire retardant of the two minerals (hydromagnesite and huntite), therefore less effort has been spent analysing possible fire retardant mechanisms of huntite. Kirschbaum [56,57] states that because of its high decomposition temperature, over $400^{\circ} \mathrm{C}$, huntite is not a very effective fire retardant on its own. He goes on to say that a combination of hydromagnesite with huntite has equal flame retardant performance to metal hydroxides such as ATH provided the hydromagnesite to huntite ratio is greater than $40 \%$. This implies that if huntite is ineffective as a fire retardant in a blend with hydromagnesite, then hydromagnesite must be a very effective fire retardant since the mixture is still as effective as ATH. Alternatively huntite is contributing some as yet unidentified fire retardant behaviour. As the ratio of hydromagnesite 
to huntite increases to $40 \%$ there is a steady increase in oxygen index but at around $40 \%$ the oxygen index plateaus with no further significant increase, even at ratios of $100 \%$ hydromagnesite[57]. Again, this suggests that the huntite is having some fire retardant effect because it has been shown[5] that ATH increases limiting oxygen index (LOI) significantly when loading levels in a polymer are raised from $40 \%$ to $60 \%$. It appears that in a mixture of hydromagnesite and huntite that the fire retardant effect of hydromagnesite is balanced by the effect of huntite once the ratio of hydromagnesite to huntite reaches $40 \%$. In EVA, blends of hydromagnesite and huntite containing more than $40 \%$ hydromagnesite are shown to give an oxygen index of $35-36 \%$ at a $60 \%$ loading level. Kirschbaum also reports that natural blends of hydromagnesite and huntite have a similar endothermicity to aluminium hydroxide and magnesium hydroxide. Kirschbaum also gives brief details[56] of how blends of hydromagnesite and huntite can increase oxygen index when used as a partial replacement for ATH in ethylene propylene diene monomer rubber (EPDM) and can be used to produce a polybutylene terephthalate (PBT) compound suitable for the electrical and electronics industry with a UL94 V0 rating in the Bunsen burner test. This shows that the combination of hydromagnesite and huntite can be more effective than ATH adding to the evidence that huntite is providing some form of fire retardant action.

Georgiades[17] reported that blends of hydromagnesite and huntite containing less than $40 \%$ of hydromagnesite struggled to achieve a UL94 V0 rating at reasonable loading levels in polypropylene and EVA. Georgiades reports that studies of mixtures of the minerals containing between $10 \%$ and $67 \%$ hydromagnesite showed that there was no significant difference in the fire retardant effect once the hydromagnesite content exceeded $42 \%$. No details are given as to what test was used to determine the fire retardancy of the compounds. It is also reported that a 50/50 mixture of the minerals and a mixture with a higher proportion of huntite are efficient smoke suppressors. This is the first positive evidence of the action that huntite is providing in terms of fire retardancy. Unfortunately these comments are made but no data is presented to back up the claims so it is impossible to draw any further conclusions.

Very little detailed research has been published on the influence of the hydromagnesite / huntite ratio of natural blends on fire retardancy in polymer compounds. Clemens[58] appears to have published the first and so far perhaps the most detailed investigation into the effect of the ratio of the two minerals. The work was conducted using polypropylene and in agreement with previously reported work the hydromagnesite component imparted significantly greater fire retardant effect than the huntite. However, fire retardancy was measured in terms of oxygen index and UL94. No measurements of smoke, heat release or other aspects of fire and combustion were examined. It was also found that huntite was much more effective than hydromagnesite at nucleating crystallisation of polypropylene. This effect was observed to give compounds improved impact properties when a higher proportion of huntite was used. A similar reinforcing nature of huntite particles was reported by Geogiades[17] and attributed to the platy nature of the huntite particles.

The work, discussed above, by Kirschbaum, Clemens, and Georgiades, while providing useful guidelines to the industrial use and applications of natural blends of hydromagnesite and huntite, has been more application oriented rather than making detailed studies of their fire retardant mechanisms. These publications appear to be more focussed on promotion of the use of these materials by the company commercialising the minerals.

Basfar[59] has shown that peroxide crosslinking of EVA containing hydromagnesite and huntite (UltraCarb LH15X) increases elongation at break significantly over a range of filler loading levels from 90 to $180 \mathrm{phr}$. At $120 \mathrm{phr}$ the elongation at break was increased from less than $200 \%$ to over $500 \%$ by crosslinking. At the same time tensile strength was shown to increase, although the magnitude of the improvement diminished with increasing filler loading levels, at $180 \mathrm{phr}$ crosslinking had no effect on tensile strength, but still improved elongation at break. In comparison, peroxide crosslinking of magnesium hydroxide filled EVA showed only small increases in elongation at break (approx. 200\% to 250\% at 120 phr loading). However, crosslinking provided a consistent increase in tensile strength over the same range of loading levels. Peroxide crosslinking consistently increased the LOI of EVA filled with hydromagnesite and huntite by $3-4$ percentage points over the range of loading levels (e.g approx. $29-33 \%$ at 120 phr loading and approx. $36-40 \%$ at 150 phr loading). The LOI 
values of the uncrosslinked magnesium hydroxide filled EVA were approximately equivalent to the values achieved with the crosslinked EVA containing hydromagnesite and huntite. However, peroxide crosslinking the magnesium hydroxide filled EVA consistently reduced the LOI values by about $3-4$ percentage points. Similarly opposing trends were reported in cone calorimeter results; peak heat release rates were reduced from $383 \mathrm{kWm}^{-2}$ to $301 \mathrm{kWm}^{-2}$ when EVA filled with $150 \mathrm{phr}$ of magnesium hydroxide was crosslinked. However, EVA filled with $150 \mathrm{phr}$ of hydromagnesite and huntite showed an increase in peak heat release rate from $310 \mathrm{kWm}^{-2}$ to $379 \mathrm{kWm}^{-2}$. Time to ignition was increased in both the EVA filled with magnesium hydroxide, and hydromagnesite and huntite when the compounds were crosslinked. Crosslinking with ionising radiation was shown to have similar effects as peroxide crosslinking on mechanical properties with both types of fire retardant mineral, but the effect on fire properties was not reported. Basfar states that it is not clear why the crosslinked EVA filled with huntite and hydromagnesite has such different mechanical properties compared to the crosslinked magnesium hydroxide filled EVA, but notes that further work is planned to examine these effects.

\section{Fire Retardancy of Synthetic Magnesium Carbonate Hydroxide Pentahydrate}

Rigolo[60] carried out some comparisons in polypropylene between a synthetic magnesium carbonate hydroxide pentahydrate (MCHP) and the commonly used flame retardants ATH and magnesium hydroxide. The MCHP was a reagent grade supplied from Aldrich Chemicals. $\mathrm{MCHP}$ is quoted as having the following chemical formula.

$$
\left(\mathrm{MgCO}_{3}\right)_{4} \cdot \mathrm{Mg}(\mathrm{OH})_{2} \cdot 5 \mathrm{H}_{2} \mathrm{O}
$$

This formula is very similar to hydromagnesite having only one extra water molecule and is the formula given by Botha[26] as heavy basic magnesium carbonate. Rigolo found it to be more effective than magnesium hydroxide in terms of oxygen index and UL94 vertical burn tests. A $60 \%$ loading of MCHP in polypropylene gave an oxygen index of $28 \%$ with a UL94 V0 rating. Both the ATH and magnesium hydroxide used in this study absorb more energy per unit mass through their endothermic decompositions than MCHP. Therefore the effectiveness of MCHP is attributed to the large loss of water and the formation of a thicker and more impermeable inorganic residue than is formed by either ATH or magnesium hydroxide. For all fillers at loadings of less than $40 \%$, the polymer could flow away from the flame, at levels of greater than $40 \%$ the samples retained their shape during burning and formed inorganic residues. In a UL94 vertical burn test a $50 \%$ loading level of MCHP was required to prevent dripping and achieve a $\mathrm{V} 0$ rating, however magnesium hydroxide required a $60 \%$ loading level to achieve the same rating. Investigation was also made into the temperature of the sample during the oxygen index test. This was done using a thermocouple embedded into the oxygen index samples at a set distance from the tip. The temperature profile was then measured as the flame front approached. It was found that MCHP filled PP took considerably longer to reach its maximum burning temperature than ATH filled PP, indicating a slower burn rate. Magnesium hydroxide gave a similar time to peak temperature as MCHP. This longer time to reach maximum burning temperature was used to show that the rate of burning of an MCHP filled PP is slower than that of an ATH filled PP. It was also observed that the temperature measured by the thermocouple in the MCHP filled polypropylene remained high for up to 90 seconds after the flame had extinguished and was accompanied by an afterglow. It is possible that this is due to the catalytic conversion of carbon to carbon dioxide by the magnesium oxide decomposition product of the MCHP. These findings are not necessarily indicative of the results that could be expected with natural hydromagnesite due to the higher water content of the MCHP or blends with huntite, as no measurements were shown for these materials. Mixtures of magnesium hydroxide and magnesium carbonate in the same ratios as seen in MCHP were found to be less effective flame retardants than MCHP. This indicates that the 5 water molecules and also possibly the combined crystalline structure of the components in MCHP is vital for the efficient fire retardant mechanism of MCHP. 


\section{Influence of Stearic Acid Coating on Fire Retardancy of Mixtures of Hydromagnesite and Huntite}

Haurie[61] reported that in EVA a 2 wt\% coating of stearic acid on synthetic hydromagnesite increased oxygen index to $32.9 \%$ compared to $24.5 \%$ for an uncoated sample, although a 4 wt $\%$ coating reduced the oxygen index back to $29.2 \%$. However, it should also be noted that the loading level of hydromagnesite in EVA varied over this test series. The uncoated sample was used at a $50 \mathrm{wt} \%$ loading, while the 2 and $4 \mathrm{wt} \%$ coated samples was used at $57 \mathrm{wt} \%$ loading. The increased loading level will have certainly also improved the oxygen index value, however the presence of stearic acid is also likely to have several effects. It will help to ensure good dispersion of the hydromagnesite, improving fire retardancy. Also its presence will slightly increase the available fuel, reducing the hydromagnesite loading. Haurie observed that the stearic acid coating increased the rate of hydromagnesite decomposition between $350^{\circ} \mathrm{C}$ and $450^{\circ} \mathrm{C}$. In comparison to a commercially available $1 \%$ stearic acid coated mixture of hydromagnesite and huntite (UltraCarb C5-10) the oxygen index of the EVA containing 1 wt\% stearic acid coated synthetic hydromagnesite was lower (31.9\% compared to $34.7 \%$ ), although it should be noted that the loading level of the synthetic material was again reduced (55 wt\% compared to $63 \mathrm{wt} \%$ ) compared to the UltraCarb C5-10. It was also noted that higher levels of stearic acid gave an improvement in tensile strength and elongation at break. Electron microscope pictures clearly show the effect of coating on improving the interaction of the polymer with the synthetic hydromagnesite particle surface. The coated samples show clear adhesion of the polymer matrix to the surface of the particles, whereas the uncoated samples sit in voids within the matrix.

\section{Fire Retardant Behaviour of Hydromagnesite / Huntite Blends in Mixtures with ATH}

Haurie[62] has also looked at magnesium hydroxide, synthetic hydromagnesite and natural hydromagnesite/huntite blends, each in a 50/50 mix with ATH. This work was done in a 75/25 LDPE/EVA blend. Oxygen index tests showed that all three fire retardants improved the oxygen index from the $18.7 \%$ measured for the polymer blend alone. The ATH/synthetic hydromagnesite blend had a slightly higher oxygen index than the $\mathrm{ATH} /$ [hydromagnesite/huntite] blend, $28.6 \%$ compared to $27.1 \%$. The $\mathrm{ATH} / \mathrm{magnesium}$ hydroxide blend sat between the two at $28.1 \%$. Cone calorimeter tests at $50 \mathrm{kWm}^{-2}$ showed that all three blends gave peak heat release rates of about $180 \mathrm{kWm}^{-2}$. However, there were differences between the burning and ash formation characteristics. The blend containing synthetic hydromagnesite had a slower reduction in heat release after the peak than either the magnesium hydroxide or the blend of natural hydromagnesite and huntite. The synthetic hydromagnesite blend also showed a second peak in heat release rate at between 450 and 550 seconds. The blend containing hydromagnesite and huntite also showed a second peak around $600-800$ seconds but it was broader and less intense than the second peak in the formulation containing the synthetic hydromagnesite. These second peaks were attributed to the collapse of the ash structure and the release of the entrapped gases. In the case of the synthetic hydromagnesite the ash had shown a large volume expansion which then collapsed completely. The sample containing natural hydromagnesite and huntite showed some expansion but did not suffer the same collapse. Haurie makes no comment on why this should be. It is possible that the platy huntite particles are providing some reinforcement to the ash structure helping to prevent the overexpansion of the structure and providing support to prevent the collapse. This kind of action by huntite may well add to the fire retardant effect of the mixture of hydromagnesite and huntite. This less obvious fire retardant action may have been overlooked in the past, leading to the misconception that huntite is an ineffective part of the blend in fire retardant terms. Smoke emission was also measured using the cone calorimeter in relation to the unfilled polymer; the synthetic hydromagnesite blend increased average specific extinction area and the total smoke released, while the magnesium hydroxide and blend of natural hydromagnesite and huntite reduced both of these parameters. Again Haurie doesn't comment but this could indicate that the huntite portion of the hydromagnesite/huntite mixture is performing a useful function. This agrees with Georgiades's observation[17] that huntite reduces smoke. If the huntite is reinforcing the char it will reduce the transport of flammable gases to the flame, therefore reducing heat release 
and smoke emissions. The synthetic hydromagnesite does not have this functionality, therefore the heat release rate is higher, and there is a second peak in heat release and smoke, as the ash loses integrity, collapsing with the release of entrapped gases.

\section{Fire Retardant Behaviour of Hydromagnesite / Huntite Blends in Mixtures with Glass Frits}

Kandola[63] investigated partial substitution of mixtures of hydromagnesite and huntite, and ATH with glass frits at replacement levels up to $50 \%$ in a vinyl ester resin. Glass frits are small friable glass particles made up of mixtures of silicon dioxide mixed with other metal oxides. In a fire situation the frits melt, flow and mix into a hard thermally insulating fire barrier. A number of patents[64-69] published over the past 10 years claim fire retardant benefits for the use of glass frits in a number of polymer systems. Kandola reported that partial replacement of a mixture of hydromagnesite and huntite with glass frits at levels up to $33 \%$ reduced the oxygen index by up to 1.5 percentage points, but a $50 \%$ replacement gave an oxygen index value similar that of the mixture of hydromagnesite and huntite alone. Partial replacement of ATH with the glass frit reduced the LOI at all levels of replacement up to $50 \%$. Cone calorimeter results showed that replacement of both ATH, and mixtures of hydromagnesite and huntite, with glass frits lead to an increase in peak heat release rate and increased smoke production. Pictures of the char residues shows that addition of the glass frits has the positive effect of producing a more coherent char structure with less cracks in the surface. This might be expected to help protect the underlying polymer during the burning process, unfortunately the oxygen index and cone calorimeter results do not show such benefits and no explanation is given as to why this might be.

\section{Heat Release Studies by Cone Calorimetry}

Morgan[70] has made some cone calorimeter studies of the effectiveness of various magnesium carbonate based fire retardants including a blend of natural hydromagnesite and huntite, synthetic hydromagnesite, magnesium carbonate, calcium carbonate and magnesium hydroxide. The work was all completed in ethylene vinyl acetate (EVA) and ethylene ethyl acrylate (EEA). There appears to be some misunderstanding about the decomposition of hydromagnesite. It is stated that "since hydromagnesite has a release temperature of $320-$ $350^{\circ} \mathrm{C}$, we used $\mathrm{Mg}(\mathrm{OH})_{2}$ as the hydroxide control sample". It has been shown by many authors[24,25,29,33,35-39,62] that hydromagnesite decomposes over a range of about $220-$ $550^{\circ} \mathrm{C}$. Morgan also states that in his electron micrographs the hydromagnesite particles "can be clearly seen amongst the larger huntite particles". This is incorrect; in the type of blends of natural hydromagnesite and huntite used in this work the huntite particles are naturally much smaller than the hydromagnesite particles.

Morgan found that in EVA, magnesium hydroxide and synthetic hydromagnesite were approximately equal in their ability to reduce peak heat release rates and extend the time to reach the peak heat release rate to a greater extent than the other fire retardant fillers included in the study. Magnesium carbonate was found to be less effective than calcium carbonate at improving these parameters, although in EEA this situation was reversed. This finding was unexpected since magnesium carbonate decomposes endothermically to produce carbon dioxide at a lower temperature than calcium carbonate. It was found that the magnesium carbonate was not decomposing under the $35 \mathrm{kWm}^{-2}$ heat flux, therefore under higher heat fluxes magnesium carbonate may become more effective. The fact that the magnesium carbonate was not decomposed means that the difference in performance could simply be down to differences in the densities of the minerals. Calcium carbonate has a density of approximately $2.8 \mathrm{~g} \mathrm{~cm}^{-3}$ compared to approximately $2.96 \mathrm{~g} \mathrm{~cm}^{-3}$ for magnesium carbonate. This means that in the calcium carbonate filled compound about $5.5 \%$ additional volume of polymer would have been replaced by inert mineral. However, calcium carbonate has a heat capacity of $0.84 \mathrm{JK}^{-1} \mathrm{~g}^{-1}[71]$ compared to $0.89 \mathrm{JK}^{-1} \mathrm{~g}^{-1}[72]$ for magnesium carbonate. Comparison of synthetic hydromagnesite with a blend of natural hydromagnesite and huntite in EVA was made. It was stated that the ratio of hydromagnesite to huntite was unknown in 
the natural blend and therefore the effect of each component cannot be explained. However, it is clear that the dilution of the natural hydromagnesite with an unknown quantity of huntite has had the positive effect of reducing the peak heat release rate, at the cost of reducing the time to ignition, when compared to the synthetic hydromagnesite. However the peak heat release rates of all the fillers was similar. The reduction in time to peak heat release rate arises because the huntite portion of the blend does not decompose until higher temperatures. Therefore during the pre-ignition stages of the fire a blend with huntite has less of the active component than a purer hydromagnesite.

Comparing the different activity of the fillers in EVA and EEA, Morgan makes the suggestion that the interactions between the differing polymers and the fillers accounts for the different fire retardant effectiveness of the fillers in the various polymers. However, no measurement or suggestion of what these different mechanisms might be is given. In summary it is reported that in EEA, hydromagnesite and magnesium hydroxide give similar HRR responses. However, in EVA, hydromagnesite and magnesium hydroxide have similar peak heat release rates but the time to ignition is much earlier for the hydromagnesite.

Morgan concludes that the huntite in blends of natural hydromagnesite and huntite reduces the effectiveness of this material and comments that the huntite has no more function than simple dilution in the manner of a calcium carbonate. It should be remembered though that all of Morgan's work was carried out at $35 \mathrm{kWm}^{-2}$ and as with magnesium carbonate, huntite will only become active at higher temperatures. The surface temperature for a non combustible board[73] at $35 \mathrm{kWm}^{-2}$ in the cone calorimeter reaches a plateau of around $500^{\circ} \mathrm{C}$ after 30 minutes. Huntite is also a very platy mineral and may act as a much more effective gas barrier and radiant heat shield than a blocky calcium carbonate. It appears that Morgan's conclusion that huntite is a simple diluent in combination with hydromagnesite is not justified by the evidence in his paper.

Most researchers make the assumption that huntite contributes less to the fire retardant effect than hydromagnesite and that a higher proportion of hydromagnesite brings benefits for fire retardancy. Very little detailed work has been reported on the fire retardant benefits, if any, that huntite brings to the mixture of minerals. Inglethorpe[30] makes brief comment that huntite may have some beneficial properties in terms of fire retardancy. It is suggested that the small particle size of the huntite, which is typically less than $2 \mu \mathrm{m}$ compared to the $5-20$ $\mu \mathrm{m}$ size of the hydromagnesite, may improve the fire retardant effectiveness of the mineral. It is also suggested that the small huntite particles could reduce smoke density by producing a high surface area magnesium oxide. These are simply made as suggestions and no work is presented to either confirm or deny these hypotheses.

\section{Effect of Hydromagnesite / Huntite Mixtures on the Burning Behaviour of Ethylene Propylene Copolymers}

Toure has published two papers detailing the use of mixtures of hydromagnesite and huntite as a fire retardant in an ethylene propylene copolymer. The first[74] of the two studies gives details of the fire retardant effects of a blend of natural hydromagnesite and huntite with a 40:60 ratio. DTA measurements show how the polymer decomposes in nitrogen at between $400^{\circ} \mathrm{C}$ and $500^{\circ} \mathrm{C}$ and that the blend of hydromagnesite and huntite has endothermic decompositions above and below the polymer decomposition temperature. Similar measurements in air of the polymer and a polymer compound containing the mineral mixture showed how the exothermic decomposition of the polymer between $320^{\circ} \mathrm{C}$ and $425^{\circ} \mathrm{C}$ was pushed to a higher temperature when the minerals were added as a fire retardant. In fire tests, increasing loading level of the blend of hydromagnesite and huntite from 0 to $48.5 \mathrm{wt} \%$ increased the oxygen index[6] from 18.3 to $24.0 \%$. The rate of horizontal flame spread measured by the French test NF P 92-504[75] was reduced from $0.64 \mathrm{mms}^{-1}$ to $0.12 \mathrm{mms}^{-1}$ over the same range of loading levels. For loading levels of over $25 \%$ no dripping occurred in the French NF P 92-505[75] dripping test. It was noted that a fire retardant effect could be expected from the endothermic decomposition of the hydromagnesite and partial decomposition of the huntite diluting the gas phase with water and carbon dioxide. Due to the fact that the polymer had completely decomposed at $500^{\circ} \mathrm{C}$, only partial decomposition of 
huntite was expected to have a significant fire retardant effect. Any further decomposition of the huntite above this temperature was said to have no effect on fire retardancy of the polymer. This would certainly be true for thermally thin polymer compounds but not valid for thermally thick materials. DTA analysis was carried out on the ash residue to confirm the state of decomposition of the minerals. It is unclear in which test the char was formed but at a loading level of $20.4 \%$ the DTA analysis shows that there is no endothermic decomposition in the temperature range $500-600^{\circ} \mathrm{C}$. This is the temperature range in which huntite is expected to endothermically decompose to magnesium oxide and calcium carbonate, indicating that at least partial degradation of the huntite occurred. However at a $48.5 \%$ loading level, a large endotherm is present in this temperature range indicating that the huntite did not decompose during combustion of the polymer. The reason given for this is that the higher loading level provides a more efficient fire retardant action, keeping the temperature of combustion to a lower temperature.

\section{Action of Hydromagnesite and Huntite as a Fire Retardant in Halogenated Formulations}

In the second paper[76] by Toure, the combination of natural hydromagnesite and huntite mixtures with antimony trioxide and decabromodiphenyl oxide (DBDPO) in ethylene propylene copolymer are investigated in some detail. The blend of natural hydromagnesite and huntite is investigated as a fire retardant in its own right as is the blend of antimony oxide with DBDPO. Combinations of the two blends are also investigated. The DBDPO and antimony trioxide act in the gas phase and it was thought that this may enhance fire retardancy in combination with the condensed phase endothermic release of water vapour and carbon dioxide from the hydromagnesite and huntite.

The endothermic decomposition of the blend of natural hydromagnesite and huntite was found to cool the substrate reducing the heat transfer to the solid phase. It was also found to dilute the gaseous phase mainly with water. The fire retardant "efficiency" of the hydromagnesite/huntite blend as measured by TGA/DTA was said not to increase steadily with loading level. However, it is important to recognise the value of TGA/DTA in understanding thermal decomposition without mistaking it for a flammability test. The reduced "efficiency" was thought to result from incomplete decomposition of the minerals at higher loading levels, due to the lack of combustible material providing thermal feedback. TGA and DTA measurements on ash residue clearly shows that where higher filler loadings are used less decomposition of the huntite had occurred. It follows that when higher loading levels of a hydromagnesite/huntite mixture are used, the decomposition of the hydromagnesite is so effective at reducing the heat of the substrate that it never reaches a high enough temperature to initiate the higher temperature decompositions of the huntite. It is not stated which test the ash residues were taken from but it was probably oxygen index as results from this test were discussed. The oxygen index test has no external heat source after ignition, relying entirely on self sustaining combustion. Therefore the huntite is less likely to decompose than in a cone calorimeter test or real fire situation where higher external heat fluxes are present.

The argument that the effectiveness of blends of hydromagnesite and huntite does not increase steadily with loading level seems to contradict the results presented. Oxygen index results showed a steady increase with increasing loading level and rate of flame spread was steadily reduced. The lack of any mechanism from the hydromagnesite/huntite blend in the gaseous phase, beyond simple dilution, is also stated as a limitation of metal hydrates and carbonates. Therefore the action of DBDPO and antimony oxide which act as free radical scavengers in the gas phase were investigated as co-additives.

The DBDPO blend with antimony trioxide is shown to work well in its own right before blends with hydromagnesite and huntite are discussed. It is reported that there are two mechanisms working against the DBDPO and antimony trioxide in these blends. The first is that magnesium oxide (a decomposition product from both hydromagnesite and huntite) is known to slow the production of gaseous halogen compounds from antimony/bromine blends[77]. The second is that the endothermic decomposition of the hydromagnesite/huntite mixture is 
shown to overlap with the exothermic decomposition of the DBDPO/antimony trioxide blend potentially reducing its effectiveness. Experiments at different loading levels of the two blends show that with a $25 \%$ loading of the hydromagnesite/huntite blend and a $20 \%$ loading of the DBDPO antimony trioxide blend, the potential antagonisms are overcome. At these levels a compound with an LOI of $26 \%$, a UL94 V0 rating and a flame spread rate of $2 \mathrm{mms}^{-1}$ is reported.

One useful side effect noted by Toure was that increasing loading levels of the hydromagnesite/huntite blend gave an increase in flexural modulus of the same order as would be expected from lamellar fillers such as talc or mica. The smaller huntite particles have a naturally platy morphology so would be expected to enhance certain physical properties.

The use of UltraCarb as a fire retardant in PVC has been published several times at conferences in the early to mid 1990's [58,78-82] and in the scientific journals[83]. These papers give some very detailed information on the use of hydromagnesite/huntite blends in PVC. In PVC, blends of hydromagnesite and huntite have been shown to increase oxygen index[56] and reduce smoke and acid gas emissions[17]. However, since hydrogen chloride is an active flame quencher in the gas phase, reaction with carbonates and hydroxides can be counter-productive.

Early work by Briggs $[80,81]$ gave details of a number of PVC formulations containing blends of hydromagnesite and huntite. It showed how flammability, smoke, acid gas and carbon monoxide emissions can all be reduced by blends of hydromagnesite and huntite. It is likely that when hydromagnesite and huntite are used in halogen containing polymers that the decomposition mechanism of both minerals will be a combination of the thermal decomposition previously discussed and reaction of acidic hydrogen halide with the carbonate mineral. The altered decomposition mechanism will lead to earlier release of carbon dioxide from the carbonate groups, with the formation of magnesium and calcium halide, reducing the volume of acid gas released into the atmosphere. Cone calorimeter data shows that time to ignition and rate of heat release are improved as the loading level of hydromagnesite and huntite are increased. NBS smoke chamber measurements show that in non-flaming mode there is a trend to lower smoke at higher loading levels. The fact that blends of hydromagnesite and huntite have a higher onset of decomposition temperature than ATH was said to allow higher extrusion speeds giving an obvious benefit to cable producers looking to increase output. Since the decomposition of PVC begins with chain stripping of hydrogen chloride and the decomposition is auto-catalytic, the presence of hydroxides and carbonates to absorb the hydrogen chloride will also improve its thermal stability. Comparisons of zinc borate and antimony trioxide as co-additives to hydromagnesite and huntite were made. It was shown that mixtures of zinc borate with hydromagnesite and huntite gave PVC compounds with lower flammability, smoke and carbon monoxide emissions compared to compounds filled with blends of chalk and antimony trioxide. A PVC compound containing hydromagnesite and huntite was also shown to give reduced flammability and marginal reductions in smoke and carbon monoxide compared to one using a phthalate plasticiser. The formulations shown in this work were all aimed at the electrical wire and cable market. It was also shown that hydromagnesite and huntite in PVC can improve electrical properties of the compound by slightly increasing resistivity. The usual trend of a reduction in electrical resistivity on the addition of fillers, particularly if the polymer is of low polarity, is less apparent with hydromagnesite/huntite mixtures providing an additional benefit compared to alternatives such as ATH.

From 1992 and 1993 Briggs continued to further develop and optimise PVC formulations containing hydromagnesite and huntite. This culminated in two very detailed papers $[82,83]$ giving details of approximately 50 different PVC formulations showing the use of hydromagnesite and huntite. This develops the initial work described above: combinations of a variety of types of plasticisers and coadditives such as antimony trioxide, zinc borate, zinc stannate, molybdenum trioxide, and a magnesium zinc complex are detailed on their own and in combination, looking for synergies with hydromagnesite and huntite. Of the two most commonly used plasticisers (diisooctyl phthalate [DOP] and diisodecyl phthalate [DIDP]) DOP was shown to give compounds with higher LOI, lower rates of heat release and lower smoke 
emissions. A pentaerythritol ester plasticiser was shown to be particularly effective at reducing smoke emissions. The use of precipitated calcium carbonate in combination with UltraCarb was shown to be effective at reducing acid gas emissions at the expense of a reduction in oxygen index. A combination of hydromagnesite and huntite with zinc borate is shown to be a particularly effective method of producing antimony free alternatives to the traditional combination of antimony trioxide and chalk in PVC for the wire and cable industry. The work gives details of how hydromagnesite and huntite can be used to produce formulations with low smoke, high oxygen index, low acid gas emissions, and goes some way to providing formulations that meet specifications such as BS7655: Specification for Insulation and Sheathing Materials for Cables.

\section{Fire Retardant Polymer Nanocomposites Containing Hydromagnesite}

The study of fire retardant properties of blends of hydromagnesite with nano clays is still in its infancy. There appears to be currently only two published[84,85] papers in this area.

Laoutid[85] showed that use of a 55\% synthetic hydromagnesite, $5 \%$ organo modified montmorillonite (oMMT) loading in EVA increased the LOI value to $34 \%$ compared to $29 \%$ for use of $60 \%$ hydromagnesite alone. It was suggested that the increase in LOI was due to reinforcement of the ash residue by the oMMT. This reinforcement of the hydromagnesite residue was also shown to lead to reduced heat release during testing on the cone calorimeter where a stable foamed residue was formed. It was suggested that the oMMT forms a barrier helping to prevent the decomposition volatiles entering the gas phase instead promoting the formation bubbles and possibly some intumescent protection of the underlying polymer. SEM observations showed that sintering of the $\mathrm{MgO}$ particles happened at temperatures between $700^{\circ} \mathrm{C}$ and $1200^{\circ} \mathrm{C}$. XRD analysis of the residues showed that at $700^{\circ} \mathrm{C} \mathrm{MgO}$ was present from the decomposition of the hydromagnesite. At $1200^{\circ} \mathrm{C}$ there had been some crystallisation of the $\mathrm{MgO}$ and also formation of small quantites of forsterite $\left(\mathrm{Mg}_{2} \mathrm{SiO}_{4}\right)$ indicating that there had been some reaction between the $\mathrm{MgO}$ and the montmorillonite at high temperature.

Initially it appears that Haurie[84] found contradictory results to Laoutid[85]. Haurie reports that a blend of hydromagnesite with oMMT gives a reduction in LOI, the opposite of Laoutid's reported increase, however Haurie's total filler content is not kept constant. Confusingly, the comparison is made between an EVA compound containing a blend of $30 \%$ ATH and $30 \%$ hydromagnesite with an EVA compound containing $27.5 \%$ each of ATH and hydromagnesite, and an EVA compound containing 30\% ATH, 15\% hydromagnesite and 5\% oMMT. The total filler content has been reduced from $55 \%$ or $60 \%$ to only $50 \%$ when the oMMT was added making the results and conclusions difficult to fully interpret and understand. An increase in time to ignition and a reduction in peak heat release rate, measured in a cone calorimeter, was attributed to the oMMT. This is clearly true from the results even at the lower total filler content of $50 \%$ compared to $55 \%$ for the compound not containing the oMMT. In fact the oMMT compound containing $50 \%$ total filler content gave time to ignition and peak heat release values between those of the compounds containing total filler contents of $55 \%$ and $60 \%$ with no oMMT. The heat release rate graphs shown by Haurie are less convincing, they clearly show that the average heat release during the entirety of the test is higher for the compound containing the oMMT, again this could be due to the lower total filler content. Haurie claims the presence of oMMT increased the stability of the char and lead to a higher mechanical cohesion of the ash crust. This comment is similar to the comment made by Laoutid that oMMT reinforces the residue.

\section{Decomposition of Hydromagnesite and Huntite When Incorporated into a Polymer Compound.}

The decomposition mechanism of hydromagnesite and huntite was discussed earlier in this paper and in greater detail elsewhere[40]. However, it is worth considering the decomposition mechanisms within the confines of a polymer matrix. Figure 6 shows the thermal decomposition of EVA containing $60 \mathrm{wt} \%$ of a natural mixture of hydromagnesite and huntite. The TGA profiles were measured by the current authors at $10^{\circ} \mathrm{Cmin}^{-1}$ in air using a TA 
Instruments Q5000. The decomposition of the EVA and the mixture of huntite and hydromagnesite were also measured individually. These profiles were then scaled and added together in order to predict the behaviour of the compound. Comparison with the actual and predicted decomposition shows that there is significant interaction between the polymer and mineral filler that was not predicted.

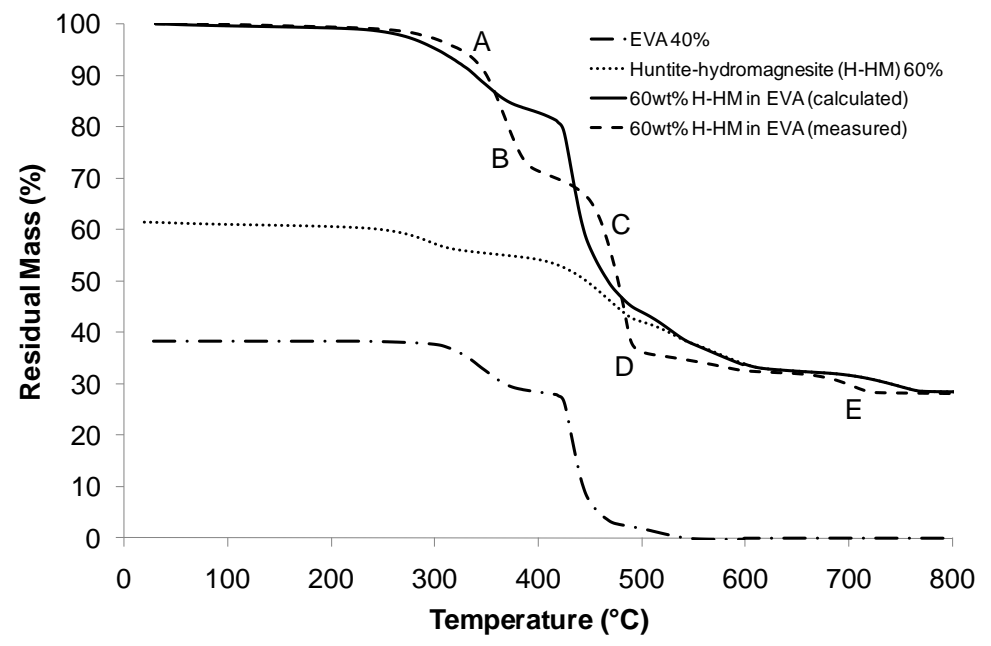

Figure 6: TGA decomposition of a mixture of natural huntite and hydromagnesite compared to an EVA compound containing $60 \mathrm{wt} \%$ of the huntite hydromagnesite mixture.

Point $A$ in Figure 6 shows that the compound does not begin to lose mass until a higher temperature than predicted. During the initial stages of hydromagnesite decomposition, between $220^{\circ} \mathrm{C}$ and $250^{\circ} \mathrm{C}$, the thermoplastic polymer matrix may have become softened but not yet decomposed. EVA has been reported $[86,87]$ to begin decomposition at about $300^{\circ} \mathrm{C}$ which is $80^{\circ} \mathrm{C}$ above the initial decomposition temperature of hydromagnesite. Water vapour will therefore form a bubble around each decomposing hydromagnesite particle. Particles that are very near to the surface of the compound will release the water vapour into the atmosphere when the pressure within the bubble causes it to escape through the surface. Water vapour further from the surface will only be released to the atmosphere when the viscosity of the polymer drops to the point at which the bubble can move through the polymer to the surface or the front of decomposing polymer reaches the bubble. This means that an EVA compound containing hydromagnesite will show no mass loss at the decomposition temperature of hydromagnesite. Hull[87,88] observed that EVA compounds containing ATH did not begin to lose mass until about $50^{\circ} \mathrm{C}$ above the decomposition temperature of the ATH. This effect is caused by entrapment of the evolved gases, it is not evidence of a change in the decomposition of hydromagnesite. Formation of entrapped bubbles will lead to an increase volume and reduction in density of the sample, therefore thermal conductivity will be decreased. If the sample is exposed to radiant heating the surface of the material will become hotter, but the underlying bulk of the material will be cooler due to the insulation effect.

At point $B$ in Figure 6 the measured mass loss becomes larger than predicted. McGarry[86] has shown that as pure EVA decomposes it forms a charred skin layer slowing the degradation of the underlying polymer. This layer can be disrupted by the release of water vapour from the decomposition of ATH increasing the rate of decomposition. The release of water from hydromagnesite will have the same effect, exposing the underlying polymer and causing faster degradation.

At point $\mathrm{C}$ the measured mass loss again becomes less than predicted. At this point it is thought that the endothermic decompositions of the hydromagnesite and the accumulation of inorganic residue slows the decomposition of the remaining polymer.

Point $D$ is interesting and does not appear to have been reported previously. The line showing the measured decomposition of the EVA compound crosses the line showing the 
decomposition of the mixture of hydromagnesite and huntite meaning that early degradation of huntite must have occurred. Clearly the degradation of the huntite has been altered because at point $E$ the final degradation step occurs at a lower temperature than measured on the mineral alone even though the polymer has completely decomposed at this point. At the present time it is unclear what is causing the early degradation of the minerals although it may be due to reaction of acetic acid from EVA with the carbonate mineral. The current authors hope to be able to report on this in the future.

Hancock[89] showed evidence for an increase in the decomposition temperature of hydromagnesite when it is incorporated into polypropylene. It was shown by DSC that a mixture of hydromagnesite and huntite has four decomposition endotherms with peaks at $275^{\circ} \mathrm{C}, 440^{\circ} \mathrm{C}, 550^{\circ} \mathrm{C}$ and $690^{\circ} \mathrm{C}$. These temperatures coincide closely with the temperatures of maximum mass loss measured by the current authors using TGA (Figure 3). Hancock's DSC measurement of polypropylene containing $60 \%$ by mass of a mixture of hydromagnesite and huntite showed an endothermic peak for the melting of polypropylene at about $180^{\circ} \mathrm{C}$ but the endothermic peaks associated with decomposition of hydromagnesite appear to have moved to about $350^{\circ} \mathrm{C}$, and $450^{\circ} \mathrm{C}$. Hancock offers little explanation for these results commenting only that a change in the decomposition profile at about $550^{\circ} \mathrm{C}$ is caused by 'magnesium carbonate, resulting from alteration of the basic magnesium carbonate'.

Within the confines of a polymer matrix the atmosphere surrounding the decomposing hydromagnesite particles will initially contain mainly water vapour and possibly some early polymer decomposition products. At higher temperatures it will contain a mixture of water vapour, polymer decomposition products, and carbon dioxide. The initial atmosphere will rapidly become saturated with water vapour meaning further evolution of water from the hydromagnesite particle is only possible through expansion of the bubble. This effect may result in water remaining within hydromagnesite particles until a higher temperature than in an open atmosphere. This must be an atmospheric saturation effect (i.e. equilibrium between decomposing hydromagnesite and its surrounding atmosphere) not an influence of the gas pressure within the bubble since Sawada[37] showed that under nitrogen, argon or carbon dioxide at pressures up to 50 atm the loss of water was unaffected.

Above $350^{\circ} \mathrm{C}$ hydromagnesite further decomposes giving off carbon dioxide which, initially, may become entrapped around the particles. It has been shown[30,31,33,35-39] that a high partial pressure of carbon dioxide or a high heating rate can cause some of the magnesium carbonate formed during the decomposition of hydromagnesite to crystallise rather than immediately decompose giving off carbon dioxide. Crystalline magnesium carbonate decomposes at a higher temperature than the non-crystalline form, causing the complete decomposition of hydromagnesite to be delayed to a higher temperature. The effect of heating rate on the decomposition of hydromagnesite is seen in Figure 4. The self generated carbon dioxide atmosphere and high heating rate within a burning polymer is also likely to have this effect. Carbon dioxide in close proximity to the hydromagnesite particle will create a high partial pressure generating favourable conditions for the magnesium carbonate to crystallise. Hancock's work[89] shows a difference in the DSC profile between $500^{\circ} \mathrm{C}$ and $600^{\circ} \mathrm{C}$ of hydromagnesite and hydromagnesite incorporated into polypropylene. This is very likely to be due to the formation and decomposition of crystalline magnesium carbonate at the higher temperature.

The decomposition temperatures of the hydromagnesite part of a blend of hydromagnesite and huntite have been reported to be affected in the presence of decabromodiphenyl oxide (DBDPO)[76]. Whilst investigating the interactions of DBDPO, antimony trioxide and a hydromagnesite/huntite blend it was shown that an apparent increase in the dehydration temperature of the hydromagnesite was achieved when a blend of equal proportions of the two additives was created. The reason put forward for this increase in decomposition temperature of the hydromagnesite was that the DBDPO fused endothermically over an approximate temperature range of $200-400^{\circ} \mathrm{C}$ which retards the decomposition of the hydromagnesite. Clearly the decomposition temperatures of DBDPO and hydromagnesite overlap and therefore the decomposition reactions could have influence in each other. Without analysis of the gases evolved it is unclear which components are decomposing over which range of temperatures and the validity of this claim is unclear without further evidence. 
While the above effects clearly have implications for the fire retardant mechanism of hydromagnesite it is not certain that any benefit in terms of increased processing temperature can be achieved. In both of the above cases (incorporation of hydromagnesite into PP and mixtures of hydromagnesite and DBDPO), the increase in decomposition temperature was measured using TGA and DSC, both of which are mechanically static tests. Processing is a dynamic process therefore at temperatures above the decomposition temperature of hydromagnesite decomposition products are more likely to be released from the polymer by the continuous movement and mixing of the polymer during the melt processing. However, it appears that no published investigation has been made into this subject.

\section{Comparison of Hydromagnesite, Huntite, Aluminium Hydroxide and Magnesium Hydroxide.}

Table 2 compares the physical properties of hydromagnesite, huntite, aluminium hydroxide and magnesium hydroxide in terms of decomposition temperature and enthalpy, volatile content and residual mass.

\begin{tabular}{|c|c|c|c|c|c|}
\hline Name & $\begin{array}{l}\text { Aluminium } \\
\text { Hydroxide }\end{array}$ & $\begin{array}{l}\text { Magnesium } \\
\text { Hydroxide }\end{array}$ & Hydromagnesite & Huntite & UltraCarb \\
\hline \multicolumn{6}{|l|}{ Chemical formula } \\
\hline & $\mathrm{Al}(\mathrm{OH})_{3}$ & $\mathrm{Mg}(\mathrm{OH})_{2}$ & $\mathrm{Mg}_{5}\left(\mathrm{CO}_{3}\right)_{4}(\mathrm{OH})_{2} \cdot 4 \mathrm{H}_{2} \mathrm{O}$ & $\mathrm{Mg}_{3} \mathrm{Ca}\left(\mathrm{CO}_{3}\right)_{4}$ & $\begin{array}{l}\text { approx. } 60: 40 \\
\text { hydromagnesite:huntite }\end{array}$ \\
\hline \multicolumn{6}{|c|}{ Onset of decomposition $\left({ }^{\circ} \mathrm{C}\right)^{\mathrm{a}}$} \\
\hline & $180-200$ & $300-320$ & $220-240$ & $\sim 400^{b}$ & $220-240$ \\
\hline \multicolumn{6}{|c|}{ Enthalpy of decomposition $\left(\mathrm{Jg}^{-1}\right)^{\mathrm{a}}$} \\
\hline & 1300 & 1450 & 1300 & $980^{c}$ & $990^{c}$ \\
\hline \multicolumn{6}{|c|}{ Volatile content by mass (\%) ${ }^{d}$} \\
\hline Water & 35 & 31 & 19 & 0 & 11 \\
\hline Carbon dioxide & 0 & 0 & 38 & 50 & 43 \\
\hline Total & 35 & 31 & 57 & 50 & 54 \\
\hline \multicolumn{6}{|c|}{ Volatile content by volume (Itr/100g at $373.15 \mathrm{~K}$ and $1 \mathrm{~atm})^{\mathrm{d}}$} \\
\hline Water & 59.4 & 52.7 & 32.3 & 0 & 14.2 \\
\hline Carbon dioxide & 0 & 0 & 26.4 & $21.6^{\mathrm{e}} \& 8.7^{f}$ & 21.8 \\
\hline Total & 59.4 & 52.7 & 58.7 & 30.3 & 36.0 \\
\hline \multicolumn{6}{|c|}{ Residue content (\%) } \\
\hline $\mathrm{Al}_{2} \mathrm{O}_{3}$ & 65 & - & - & - & - \\
\hline $\mathrm{MgO}$ & - & 69 & 43 & 34 & 40 \\
\hline $\mathrm{CaO}$ & - & - & - & 16 & 6 \\
\hline \multicolumn{6}{|c|}{$\begin{array}{l}\text { Notes: } \\
\text { a - figures taken from Rothon[5] } \\
\text { b - taken from Figure } 3 \\
c-\text { author's own work } \\
d \text { - calculated theoretical values } \\
\text { e - initial decomposition } \mathrm{Mg}_{3} \mathrm{Ca}(\mathrm{C} \\
\mathrm{f}-\text { secondary decomposition } \mathrm{CaC}\end{array}$} \\
\hline
\end{tabular}

Table 2: Summary of the type and quantity of decomposition products produced by aluminium hydroxide, magnesium hydroxide, hydromagnesite, and huntite.

The data shows that hydromagnesite has a similar decomposition enthalpy to aluminium hydroxide, although the heat capacity of aluminium hydroxide is slightly higher than hydromagnesite (Table 3) in terms of $\mathrm{Jg}^{-1} \mathrm{~K}^{-1}$. However, hydromagnesite loses a higher proportion by mass on decomposition than aluminium hydroxide but produces about the same volume of volatiles. Aluminium hydroxide produces water as the only volatile decomposition product, whereas hydromagnesite produces a mixture of carbon dioxide and water consisting of approximately $55 \%$ water vapour and $45 \%$ carbon dioxide by volume. The heat capacities, 
in terms of $\mathrm{Jmol}^{-1} \mathrm{~K}^{-1}$ shown in Table 3, of water vapour and carbon dioxide are similar. In terms of fire retardant effect the volume of mixed gases and the effect on the heat capacity of the mixed gases entering a flame from the decomposition of hydromagnesite is likely to be similar to that of the water vapour given off by aluminium hydroxide. Aluminium hydroxide leaves an aluminium oxide residue of approximately $65 \%$ of its original mass compared to hydromagnesite which leaves a residue of magnesium oxide of only $43 \%$ of its original mass. The heat capacity in terms of $\mathrm{Jg}^{-1} \mathrm{~K}^{-1}$ (Table 3 ) of aluminium oxide is lower than that of magnesium oxide, however, taking into account the mass of residue formed gives values of $0.50 \mathrm{JK}^{-1}$ and $0.40 \mathrm{JK}^{-1}$ for the total mass of residue formed from 1 gram of aluminium hydroxide and 1 gram of hydromagnesite respectively. The fact that aluminium oxide produces a larger quantity of residue with a higher total heat capacity would seem to indicate an advantage in favour of aluminium hydroxide over hydromagnesite in terms of fire retardancy. Another may be the promotion of afterglow by the freshly formed alumina[90]. However, the fact that a number of researchers have found hydromagnesite to perform very similarly in terms of fire retardancy indicates that there must be other factors involved in its fire retardant mechanism. One such factor may be that hydromagnesite decomposes over a wider temperature range than aluminium hydroxide allowing it to continue diluting the flame and cooling the solid phase over a longer time period. In natural mixtures of hydromagnesite and huntite, the presence of huntite results in a lower total volume of volatile decomposition products from the minerals when compared to the same mass of pure hydromagnesite; the actual volume will depend on the ratio of the two minerals. Even so, it has been shown by several researchers, and discussed in this article, that these kinds of mixtures perform very similarly to aluminium hydroxide and magnesium hydroxide in terms of fire retardancy. The huntite portion of the blend must therefore be contributing to the fire retardant action, perhaps as a platy barrier layer but not just through endothermic decomposition.

\begin{tabular}{|c|c|c|c|}
\hline & Chemical formula & $\begin{array}{l}\text { Heat Capacity } \\
\left(\mathrm{Jmol}^{-1} \mathrm{~K}^{-1}\right)\end{array}$ & $\begin{array}{l}\text { Heat Capacity } \\
\left(\mathrm{Jg}^{-1} \mathrm{~K}^{-1}\right)\end{array}$ \\
\hline $\begin{array}{l}\text { Aluminium hydroxide } \\
\text { Magnesium hydroxide } \\
\text { Hydromagnesite } \\
\text { Huntite }\end{array}$ & $\begin{array}{l}\mathrm{Al}(\mathrm{OH})_{3} \\
\mathrm{Mg}(\mathrm{OH})_{2} \\
\mathrm{Mg}_{5}\left(\mathrm{CO}_{3}\right)_{4}(\mathrm{OH})_{2} \cdot 4 \mathrm{H}_{2} \mathrm{O} \\
\mathrm{Mg}_{3} \mathrm{Ca}\left(\mathrm{CO}_{3}\right)_{4}\end{array}$ & $\begin{array}{l}93.1^{\mathrm{a}} \\
77.0^{\mathrm{a}} \\
526.6^{\mathrm{b}} \\
310.1^{\mathrm{c}}\end{array}$ & $\begin{array}{l}1.20 \\
1.33 \\
1.13 \\
0.88\end{array}$ \\
\hline $\begin{array}{l}\text { Water vapour (measured at } 500 \mathrm{~K} \text { ) } \\
\text { Carbon dioxide } \\
\text { Aluminium oxide } \\
\text { Magnesium oxide } \\
\text { Calcium oxide }\end{array}$ & $\begin{array}{l}\mathrm{H}_{2} \mathrm{O} \\
\mathrm{CO}_{2} \\
\mathrm{Al}_{2} \mathrm{O}_{3} \\
\mathrm{MgO} \\
\mathrm{CaO}\end{array}$ & $\begin{array}{l}35.22^{d} \\
37.12^{d} \\
78.77^{d} \\
37.01^{d} \\
42.09^{d}\end{array}$ & $\begin{array}{l}1.96 \\
0.77 \\
0.77 \\
0.93 \\
0.75\end{array}$ \\
\hline $\begin{array}{l}\text { Notes: } \\
\text { a - figures taken from Ashton[91] } \\
\text { b - figures taken from Robie[92] }\end{array}$ & 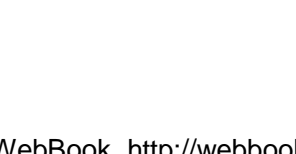 & 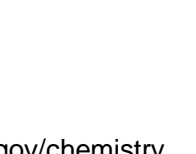 & \\
\hline
\end{tabular}

Table 3: Heat capacities at $298 \mathrm{~K}$

\section{Conclusions}

It is clear that the decomposition mechanism of hydromagnesite is complicated and influenced by a number of factors, including heating rate and composition of the atmosphere, especially the partial pressure of carbon dioxide. When contained within a polymer matrix, the carbon dioxide given off by a decomposing hydromagnesite particle is likely, at least initially, to be entrapped within a polymer bubble surrounding the particle. This entrapped carbon dioxide may well create a localised high partial pressure of the gas affecting the mechanism by which decomposition occurs. This could lead to the type of decomposition resulting in the exothermic crystallisation of magnesium carbonate. However, in mixtures of hydromagnesite with huntite the endothermic decomposition of the huntite overlaps with the exothermic event in the hydromagnesite helping to eliminate any negative effect this may have on fire retardancy. 
The evidence points to mixtures of hydromagnesite and huntite being more effective than would be expected from the evolution of inert gases and endothermicity. Many researchers have assumed that huntite is acting merely as a diluent filler. However, blends of hydromagnesite and huntite have been shown many times to have similar fire retardant properties to ATH at the same loading levels. This indicates that the wider decomposition range of hydromagnesite as well as the huntite portion of the mixtures must be contributing to the fire retardancy. Huntite will contribute to the formation of an inorganic residue, its platy nature may also act to reinforce this residue. A further mechanism by which huntite may be contributing is through its full or partial endothermic decomposition at temperatures above $450^{\circ} \mathrm{C}$. This would provide cooling to the residue layer further reducing the heat transfer to the underlying polymer.

Mixtures of hydromagnesite and huntite have been shown to provide fire retardant properties as good as or better than ATH or magnesium hydroxide in non-halogen as well as halogen containing compounds. In PVC compounds the carbonate nature of both hydromagnesite and huntite make them reactive with acids reducing the yields of acidic hydrogen chloride gas and promoting the decomposition of the carbonate.

Although blends of hydromagnesite and huntite improve fire properties in a range of polymers the mechanisms by which they function are still not fully understood. 


\section{References}

1. Bolger R. Flame retardant minerals bromine issue smoulders on. Ind. Miner. Jan 1996:2939

2. Weil ED, Levchik SV. Flame Retardants in Commercial Use or Development for Polyolefins. J. Fire Sci. 2008;26:5-43

3. Horn WE. Inorganic Hydroxides and Hydroxycarbonates: Their Function and Use as Flame-Retardant Additives, in Grand AF, Wilkie CA, editors. Fire Retardancy of Polymeric Materials. New York, Marcel Dekker, 2000, pp 285-352

4. Horrocks AR, Price D: Fire Retardant Materials. Cambridge, Woodhead Publishing, 2001

5. Rothon RN. Effects of Particulate Fillers on Flame Retardant Properties of Composites, in Rothon RN, editor. Particulate Filled Polymer Composites. Shrewsbury, Rapra Technology Ltd, 2003, pp 263-302

6. BS ISO EN 4589-1 Plastics - Determination of Burning Behaviour by Oxygen Index: Part 2 Ambient Temperature Test. 1999

7. Khalturinskii NA, Berlin AA. On reduction of combustibility of polymeric materials. International. J. Polym. Mater. 1990;14:109-125

8. Lewin M, Weil ED. Mechanisms and modes of action in flame retardancy of polymers, in Horrocks AR, Price D, editors. Fire Retardant Materials. Cambridge UK, Woodhead Publishing, 2001, pp 31-68

9. Rothon RN, Hornsby PR. Flame retardant effects of magnesium hydroxide. Polym. Degrad. Stab. 1996;54:383-385

10. Hornsby PR, Watson CL. A study of the mechanism of flame retardance and smoke suppression in polymers filled with magnesium hydroxide. Polym. Degrad. Stab. 1990;30:7387

11. Hornsby PR, Watson CL. Mechanism of Smoke Suppression and Fire Retardancy in Polymers Containing Magnesium Hydroxide Filler. Plast. Rub. Proc. Appl. 1989;11:45-51

12. Hornsby PR, Watson CL. Magnesium Hydroxide - a Combined Flame Retardant and Smoke Suppressant Filler for Thermoplastics. Plast. Rub. Proc. Appl. 1986;6:169-175

13. Camino G, Maffezzoli A, Braglia M, De Lazzaro M, Zammarano M. Effect of hydroxides and hydroxycarbonate structure on fire retardant effectiveness and mechanical properties in ethylene-vinyl acetate copolymer. Polym. Degrad. Stab. 2001;74:457-464

14. Jiao CM, Wang ZZ, Ye Z, Hu Y, Fan WC. Flame Retardation of Ethylene-Vinyl Acetate Copolymer Using Nano Magnesium Hydroxide and Nano Hydrotalcite. J. Fire Sci. 2006;24:47-64

15. Kuila T, Srivastava SK, Bhowmick AK, Saxena AK. Thermoplastic polyolefin based polymer - blend-layered double hydroxide nanocomposites. Compos. Sci. Technol. 2008;68:3234-3239 
16. Zhang G, Ding P, Zhang M, Qu B. Synergistic effects of layered double hydroxide with hyperfine magnesium hydroxide in halogen-free flame retardant EVA/HFMH/LDH nanocomposites. Polym. Degrad. Stab. 2007;92:1715-1720

17. Georgiades GN, Larsson BJ, Pust C. Huntite-hydromagnesite production and applications. Proceedings $12^{\text {th }}$ Industrial Minerals Congress 1996:57-60

18. Akao M, Iwai S. The hydrogen bonding of hydromagnesite. Acta Crystallogr. B. 1977;33:1273-1275

19. Akao M, Maruma F, Iwai S. The crystal structure of hydromagnesite. Acta Crystallogr. B. 1974;30:2670-2672

20. Faust GT. Huntite, A New Mineral. Am. Mineral. 1953;38:4-24

21. Graf DL, Bradley WF. The crystal structure of huntite, $\mathrm{Mg}_{3} \mathrm{Ca}\left(\mathrm{CO}_{3}\right)_{4}$. Acta Crystallogr. 1962;15:238-242

22. Murdoch J. Unit Cell of Hydromagnesite. Am. Mineral. 1954;39:24-29

23. Rogers AF. Crystallography of Hydromagnesite. Am. J. Sci. 1923;6:37-47

24. Beck CW. Differential Thermal Analysis Curves of Carbonate Minerals. Am. Mineral. 1950;35:985-1013

25. Botha A, Strydom C. DTA and FT-IR analysis of the rehydration of basic magnesium carbonate. J. Therm. Anal. Calorim. 2003;71:987-996

26. Botha A, Strydom CA. Preparation of a magnesium hydroxy carbonate from magnesium hydroxide. Hydrometallurgy. 2001;62:175-183

27. Choudhary VR, Pataskar SG, Gunjikar VG, Zope GB. Influence of preparation conditions of basic magnesium carbonate on its thermal analysis. Thermochim. Acta. 1994;232:95-110

28. Frost RL, Hales MC, Locke AJ, Kristof J. Controlled Rate Thermal Analysis of Hydromagnesite. J. Therm. Anal. Calorim. 2008;92:893-897

29. Haurie L, Fernandez Al, Velasco JI, Chimenos JM, Lopez-Cuesta JM, Espiell F. Effects of milling on the thermal stability of synthetic hydromagnesite. Mater. Res. Bull. 2007;42:10101018

30. Inglethorpe SDJ, Stamatakis MG. Thermal decomposition of natural mixtures of hydromagnesite and huntite from Kozani, Northern Greece. Mineral Wealth. 2003:7-18

31. Khan N, Dollimore D, Alexander K, Wilburn FW. The origin of the exothermic peak in the thermal decomposition of basic magnesium carbonate. Thermochim. Acta. 2001;367368:321-333

32. Ozao R, Otsuka R. Thermoanalytical investigation of huntite. Thermochim. Acta. 1985;86:45-58

33. Padeste C, Oswald HR, Reller A. The thermal behaviour of pure and nickel-doped hydromagnesite in different atmospheres. Mater. Res. Bull. 1991;26:1263-1268

34. Rajeswara R, Chohan VS. Kinetics of Thermal Decomposition of Hydromagnesite. Chem. Eng. Technol. 1995;18:359-363 
35. Sawada Y, Uematsu K, Mizutani N, Kato M. Thermal decomposition of hydromagnesite 4MgCO3·Mg(OH)2·4H2O. J. Inorg. Nucl. Chem. 1978;40:979-982

36. Sawada Y, Uematsu K, Mizutani N, Kato M. Thermal decomposition of hydromagnesite $4 \mathrm{MgCO} 3-\mathrm{Mg}(\mathrm{OH}) 2-4 \mathrm{H} 2 \mathrm{O}$ under different partial pressures of carbon dioxide. Thermochim. Acta. 1978;27:45-59

37. Sawada Y, Yamaguchi J, Sakurai O, Uematsu K, Mizutani N, Kato M. Thermal decomposition of basic magnesium carbonates under high-pressure gas atmoshpheres. Thermochim. Acta. 1979;32:277-291

38. Sawada Y, Yamaguchi J, Sakurai O, Uematsu K, Mizutani N, Kato M. Thermogravimetric study on the decomposition of hydromagnesite $4 \mathrm{MgCO} 3 \cdot \mathrm{Mg}(\mathrm{OH}) 2 \cdot 4 \mathrm{H} 2 \mathrm{O}$. Thermochim. Acta. 1979;33:127-140

39. Sawada Y, Yamaguchi J, Sakurai O, Uematsu K, Mizutani N, Kato M. Isothermal differential scanning calorimetry on an exothermic phenomenon during thermal decomposition of hydromagnesite $4 \mathrm{MgCO} 3 \cdot \mathrm{Mg}(\mathrm{OH}) 2 \cdot 4 \mathrm{H} 2 \mathrm{O}$. Thermochim. Acta. 1979;34:233-237

40. Hollingbery LA, Hull TR. The Thermal Decomposition of Huntite and Hydromagnesite - A Review. Thermochim. Acta. 2010;In Press

41. Teir S, Eloneva S, Fogelholm C, Zevenhoven R. Fixation of Carbon Dioxide by Producing Hydromagnesite from Serpentine. Appl. Energ. 2009;86:214-218

42. Barbieri M, Calderoni G, Cortesi C, Fornaseri M. Huntite, A mineral used in antiquity. Archaeometry. 1974;16:211-220

43. Kangal $O$, Güney A. A new industrial mineral: Huntite and its recovery. Miner. Eng. 2006;19:376-378

44. Todor DN: Thermal Analysis of Minerals. Kent, England, Abacus Press, 1976

45. Nahdi K, Rouquerol F, Trabelsi Ayadi $\mathrm{M}$. $\mathrm{Mg}(\mathrm{OH}) 2$ dehydroxylation: A kinetic study by controlled rate thermal analysis (CRTA). Solid State Sci. 2009;11:1028-1034

46. Liodakis S, Antonopoulos I. Evaluating the fire retardation efficiency of diammonium phosphate, ammonium sulphate and magnesium carbonate minerals on Pistacia lentiscus $L$. First International Symposium on Environment Identities and Mediterranean Area, ISEIMA '06. 2006:35-39

47. Liodakis S, Antonopoulos I, Agiovlasitis IP, Kakardakis T. Testing the fire retardancy of Greek minerals hydromagnesite and huntite on WUI forest species Phillyrea latifolia L. Thermochim. Acta. 2008;469:43-51

48. Liodakis S, Antonopoulos I, Tsapara V. Forest fire retardancy evaluation of carbonate minerals using DTG and LOI. J. Therm. Anal. Calorim. 2009;96:203-209

49. Liodakis S, Agiovlasitis IP, Antonopoulos I, Stamatakis MG. Fire retarding performance of hydromagnesite on forest species from a wildland/urban interface area in Athens. For. Ecol. Manage. 2006;234:S126-S126

50. Liodakis S, Antonopoulos I, Kakardakis T. Evaluating the use of minerals as forest fire retardants. Fire Saf. J. 2010;45:98-105 
51. Bensalem A, Chang W, Fournier A, Kallianos G, Paine J, Podraza K, Schleich D, Seeman J. Smoking Article Wrapper Having Filler of Hydromagnesite / Magnesium Hydroxide and Smoking Article made with said Wrapper. US Patent 5,979,461 1999

52. Bensalem A, Chang W, Fournier JA, Kallianos AG, Paine J, Podraza K, Schleich D, Seeman J. Hydromagnesite / Magnesium Hydroxide Fillers for Smoking Article Wrappers and Methods for making Same. US Patent 5,927,288 1999

53. Alternative FR filler for rubber and plastics. Plastics and Rubber Weekly. 1988:10

54. Mineral Fire Retardant Filler Suppresses Smoke. European Plastics News. 1988;15:40

55. Mineral Filler is Flame Retardant, Smoke Suppressor. Modern Plastics International. $1990 ; 20: 10 / 2$

56. Kirschbaum GS. Huntite/hydromagnesite - Mineral Flame Retardants as Alternative and Complement to Metal Hydroxides. Proceedings Flame Retardants '98. London. 1998:151-161

57. Kirschbaum G. Minerals on Fire: Flame Retardants Look to Mineral Solutions. Industrial Minerals. 2001:61-67

58. Clemens ML, Doyle MD, Lees GC, Briggs CC, Day RC. Non-Halogenated Flame Retardant for Polypropylene. Proceedings Flame Retardants '94. London. 1994:193-202

59. Basfar AA, Bae HJ. Influence of Magnesium Hydroxide and Huntite Hydromagnesite on Mechanical Properties of Ethylene Vinyl Acetate Compounds Cross-linked by DiCumyl Peroxide and lonizing Radiation. J. Fire Sci. 2010;28:161-180

60. Rigolo M, Woodhams RT. Basic magnesium carbonate flame retardants for polypropylene. Polym. Eng. Sci. 1992;32:327-334

61. Haurie L, Fernández AI, Velasco JI, Chimenos JM, Ticó-Grau JR, Espiell F. Synthetic Hydromagnesite as Flame Retardant. A Study of the Stearic Coating Process. Macromol. Symp. 2005;221:165-174

62. Haurie L, Fernández Al, Velasco JI, Chimenos JM, Lopez Cuesta J, Espiell F. Synthetic hydromagnesite as flame retardant. Evaluation of the flame behaviour in a polyethylene matrix. Polym. Degrad. and Stab. 2006;91:989-994

63. Kandola BK, Pornwannachai W. Enhancement of Passive Fire Protection Ability of Inorganic Fire Retardants in Vinyl Ester Resin Using Glass Frit Synergists. J. Fire Sci. 2010: DOI 10.1177/0734904109361015

64. Geoffrey C. Fire-retardant additives and their uses. EU Patent 04203021991

65. Jachimi R. Intumescent one-component sealant. US Patent 55940461997

66. Nguyen DT, Langille KB, Veinot DW, Bernt JO. Compound of intumescent powder and thermoplastic material. US Patent 6790893 B2 2004;

67. Seii U, Katsuji T. Fire retardant and fire resistant ethylene-propylene-diene copolymer composition and low voltage fire resistant wire/cable. JP Patent 20071694152007

68. Shoichiro N. Fire resistant silicone resin composition and low voltage fire resistant cable. JP Patent 20051711912005 
69. Spano VW. Passive fire protection. US Patent 56436611997

70. Morgan AB, Cogen JM, Opperman RS, Harris JD. The effectiveness of magnesium carbonate-based flame retardants for poly(ethylene-co-vinyl acetate) and poly(ethylene-coethyl acrylate). Fire Mater. 2007;31:387-410

71. Staveley LAK, Linford RG. The heat capacity and entropy of calcite and aragonite, and their interpretation. J. Chem. Thermodyn. 1969;1:1-11

72. Anderson CT. The Heat Capacities of Magnesium, Zinc, Lead, Manganese and Iron Carbonates at Low Temperatures1. J. Am. Chem. Soc. 1934;56:849-851

73. Schartel B, Hull TR. Development of fire-retarded materials - Interpretation of cone calorimeter data. Fire Mater. 2007;31:327-354

74. Touré B, Lopez-Cuesta J, Benhassaine A, Crespy A. The Combined Action of Huntite and Hydromagnesite for Reducing Flammability of an Ethylene-Propylene Copolymer. Int. J. Polym. Anal. Ch. 1996;2:193-202

75. Mitzlaff M, Troitzsch J. Building, in Troitzsch J, editor. Plastics Flammability Handbook. Munich, Hanser, 2004, pp 227-432

76. Toure B, Cuesta JL, Gaudon P, Benhassaine A, Crespy A. Fire resistance and mechanical properties of a huntite/hydromagnesite/antimony trioxide/decabromodiphenyl oxide filled PP-PE copolymer. Polym. Degrad. Stab. 1996;53:371-379

77. Wagner ER, Joesten BL. Halogen-modified impact polystyrenes: Quantification of preflame phenomena. J. Appl. Polym. Sci. 1976;20:2143-2155

78. Briggs C, Rutherford A, Unique Flame Retardant Filler for Pe and Other Cable Compounds. Proceedings Antec '90. Dallas, Texas. 1990:1216-1221

79. Briggs CC. Ultracarb: The natural flame retardant. Proceedings Fillers and Additives in Plastics '91 European Technical Conference. Lund, Sweden. 1991:20

80. Briggs CC, Bhardwaj B, Gilbert M. Flame Retardant PVC Cable Compounds using Huntite-Hydromagnesite. Proceedings Filplas '92. Manchester. UK. 1992

81. Briggs CC. Reduced Hazard Flame Retardant PVC Compounds. Proceedings PVC '93. Brighton. UK. 1993

82. Briggs CC, Day RC, Gilbert M, Hollingbery LA. Optimising Fire Properties for Plasticised PVC Compounds. Proceedings PVC '96. Brighton. UK. 1996:269-280

83. Briggs CC, Hollingbery LA, Day RC, Gilbert M. Optimising fire properties of plasticised poly(vinyl chloride) compounds. Plast. Rub. Compos. Pro. 1997;26:66-77

84. Haurie L, Fernández Al, Velasco JI, Chimenos JM, Lopez Cuesta J, Espiell F. Thermal stability and flame retardancy of LDPE/EVA blends filled with synthetic hydromagnesite/aluminium hydroxide/montmorillonite and magnesium hydroxide/aluminium hydroxide/montmorillonite mixtures. Polym. Degrad. Stab. 2007;92:1082-1087

85. Laoutid F, Gaudon P, Taulemesse J-, Lopez Cuesta JM, Velasco JI, Piechaczyk A. Study of hydromagnesite and magnesium hydroxide based fire retardant systems for ethylene-vinyl acetate containing organo-modified montmorillonite. Polym. Degrad. Stab. 2006;91:30743082 
86. McGarry K, Zilberman J, Hull TR, Woolley WD. Decomposition and combustion of EVA and LDPE alone and when fire retarded with ATH. Polym. Int. 2000;49:1193-1198

87. Hull TR, Wills CL, Artingstall T, Price D, Milnes GJ. Mechanisms of Smoke and CO Suppression from EVA Composites, in LeBras M, Bourbigot S, Duquesne S, Jama C, Wilkie C, editors. Fire Retardancy of Polymers: New Applications of Mineral Fillers, Royal Society of Chemistry, 2005, pp 372-385

88. Hull TR, Price D, Liu Y, Wills CL, Brady J. An investigation into the decomposition and burning behaviour of Ethylene-vinyl acetate copolymer nanocomposite materials. Polym.

Degrad. Stab. 2003;82:365-371

89. Hancock M, Rothon RN. Principle Types of Particulate Fillers, in Rothon RN, editor. Particulate Filled Polymer Composites. Shrewsbury, Rapra Technology Ltd, 2003, pp 53-100

90. Hull TR, Quinn RE, Areri IG, Purser DA. Combustion toxicity of fire retarded EVA. Polym. Degrad. Stab. 2002;77:235-242

91. Ashton HC. Fire Retardants, in Xanthos M, editor. Functional Fillers for Plastics. Weinheim, Wiley-VCH Verlag, 2005, pp 285-315

92. Robie RA, Hemingway B. Heat-Capacities at Low-Temperatures and Entropies at 298.15 $\mathrm{K}$ of Nesquehonite, MgCO3.3H2O, and Hydromagnesite. Am. Mineral. 1972;57:1768-1781

93. Hemingway B, Robie RA. Heat-Capacities at Low-Temperatures and Entropies at 298.15 K of Huntite, and Artinite. Am. Mineral. 1972;57:1754-1767 